\title{
A ruptura com a senzala: entrevista com Célio Viana
}

\section{The rupture with the slave house: interview with Célio Viana}

\author{
Selmo Nascimento da Silva \\ Doutorando em História pela Universidade Federal Fluminense \\ Professor do Departamento de Sociologia do Colégio Pedro II \\ selmons2000@gmail.com
}

\begin{abstract}
Resumo: Trata-se de entrevista de Célio Viana - liderança dos trabalhadores no serviço de limpeza urbana (garis) da cidade do Rio de Janeiro - concedida ao pesquisador e professor do Colégio Pedro II, Selmo Nascimento da Silva. Célio despontou como uma importante liderança sindical durante a greve dos garis de fevereiro de 2014. Nesta entrevista, revela sua experiência e dos demais companheiros na organização da Comissão de Greve, responsável pela direção política do movimento paredista de 2014.
\end{abstract}

Palavras-chaves: Sociologia do Trabalho. Proletariado. Limpeza Urbana. Greves. Autonomia.

\begin{abstract}
This is Celio Viana's interview - leadership of the workers in the urban cleaning service (street sweepers) of the city of Rio de Janeiro - granted to the researcher and professor at the Colegio Pedro II, Selmo Nascimento da Silva. Celio has emerged as an important union leadership during the strike by street sweepers February 2014. In this interview, he reveals his experience and other comrades to organize the Strike Committee, responsible for political direction the 2014 striker movement.
\end{abstract}

Keywords: Labour Sociology. Proletariat. Street-sweeper. Strikes. Autonomy.

Originais recebidos em: 01/07/2015

Aceito para publicação: 17/09/2015

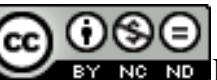

EY NC ND Este trabalho está licenciado sob uma Licença Creative Commons Atribuição-Uso NãoComercial-Vedada a criação de obras derivadas 3.0 Unported License. 


\section{Introdução}

Célio Viana, gari, 49 anos, 13 anos de trabalho na Companhia de Limpeza Urbana do Rio de Janeiro (COMLURB), despontou como uma importante liderança sindical durante a greve dos garis de fevereiro de 2014.

Ao conceder esta entrevista para Selmo Silva, Célio conta de sua experiência e dos demais companheiros na organização da Comissão de Greve, responsável pela direção política do movimento paredista de 2014. Em um "papo-reto", como se diz na gíria, o gari conta que tiveram que enfrentar a burocracia sindical para a deflagração do movimento e, depois, enfrentaram as perseguições políticas, expressas principalmente nas demissões, promovidas pela prefeitura e pela presidência da COMLURB.

Seu depoimento é o relato de uma experiência fundamental da luta dos trabalhadores, mas também é uma importante denúncia das atuais perseguições políticas e demissões promovidas para penalizar os garis que decidiram "romper com a senzala".

\section{$* * *$}

Selmo Nascimento da Silva (SNS): Companheiro Célio, faça uma apresentação inicial.

Célio Viana (CV): Meu nome é Célio Viana, tenho 49 anos, trabalho na COMLURB há 13 anos. É um trabalho que gosto de realizar, porém, ao longo do tempo pude constatar vários tipos de insatisfação por parte de meus companheiros de trabalho e a partir dessas reclamações e na minha própria visão do dia a dia, vi que realmente era necessário nos organizarmos para começarmos a reivindicar melhorias no nosso cotidiano de trabalho e nas nossas condições e na questão salarial também.

SNS: Como está a luta dos garis hoje no Rio de Janeiro?

CV: A luta do gari no Rio de Janeiro é uma luta que acredito que é muito grande, é uma luta que tem que ser incansável, porque reparações há de serem feitas, porque há muitos anos o trabalhador, o gari, vem sofrendo discriminação pelo trabalho que ele exerce. Muitas das vezes o gari foi invisível, mas as pessoas não deixaram de reparar nas ruas limpas. Não sabiam que por trás daquelas ruas limpas tinha um trabalhador que mantinha a cidade impecável. A luta do gari é uma luta que vamos ter que seguir adiante em virtude dos acontecimentos que vem surgindo pós 2014. 
SNS: Quais foram esses acontecimentos?

CV: Em 2014 nós fizemos uma greve vitoriosa, onde os trabalhadores tiveram um aumento inédito de 37\%. Quem conseguiu esse aumento foi a categoria, não foi o sindicato, porque o sindicato sempre fez acordo por baixo dos panos em conchavo com a Prefeitura e com a COMLURB, não priorizavam o aumento real do trabalhador. E nós, enquanto trabalhadores, nos organizamos e fomos à luta para reivindicar direitos e conquistamos $37 \%$ de aumento e ticket alimentação no valor de vinte reais. E a partir dali começamos a perceber que a COMLURB não gostou do trabalhador, que há muitos anos vivia num regime escravocrata como hoje ele vive, ter tirado a mordaça da boca, ter arrebentado as correntes de seus braços e ter respirado um oxigênio que faltava para poder ir à luta. A partir daí a COMLURB começou a perseguir trabalhadores, demitindo por justa causa por ter aderido ao movimento de greve. Em 2014 nós fizemos vários atos, inclusive fomos ao sindicato fazer um ato contra essa covardia, muitos trabalhadores estavam falando que tinham sido demitidos. Não sabemos o número exato, porque a COMLURB omitia esses dados, o sindicato omitia esses dados, mas por coincidência companheiros me entregaram documento que mostrava que mais de duzentos trabalhadores, pós-greve 2014 até setembro, tinham sido demitidos por justa causa. Temos documentos que provam isso.

Em 2015 voltamos às ruas em virtude do arrocho salarial aplicado pelo governo. Nós entendemos que o trabalhador não pode pagar pela crise criada pelo governo, nós temos que ter uma vida social digna. Nosso trabalho é um trabalho importante e fomos para a rua garantir o nosso direito de greve que é garantido na constituição brasileira no seu artigo nono. Com esse feito, nos foi oferecido por parte da COMLURB, obviamente combinaram com sindicato e Prefeitura, um aumento de 3\%, um aumento muito abaixo da inflação que não contemplava a categoria. Nós levamos uma proposta a ser discutida com a gestão da COMLURB, eles não tiveram o mínimo carinho de sentar e debater conosco, discutir o que seria melhor para nós. Apenas ofereceram 3\%, o que deixou a categoria muito insatisfeita e chateada.

Meses antes, a COMLURB havia nos dito que emitiu um documento parabenizando os trabalhadores pelo trabalho realizado no ano novo e no carnaval, pelo excelente trabalho que tínhamos realizado, e como prêmio recebemos um aumento de $3 \%$. Foi criada uma assembleia no dia, não lembro a data agora, e nessa assembleia estavam mais de mil e quinhentos trabalhadores que não aceitaram a proposta da 
COMLURB. Por mais que o sindicato tentasse dizer para os trabalhadores que não era pra nós tomarmos uma atitude, os trabalhadores de forma unânime decidiram que tínhamos que fazer a greve naquela data. A assembleia é soberana e o sindicato acatou a determinação da categoria, mas dificultou a emissão de documento de comprometimento, se comprometendo em decretar a greve da mesma forma que aconteceu em 2014. Mas dessa vez eles não recuaram, falaram que estavam conosco na greve. E em virtude dessa greve, conseguimos arrancar $8 \%$ de aumento, hora extra pros trabalhadores que trabalham em caminhão que nós chamamos de B.A. Infelizmente o sindicato fez uma assembleia no Ministério Público do Trabalho onde tinha poucos trabalhadores, uma assembleia esvaziada, onde a maior parte dos trabalhadores que estava ali era do sindicato, eles terminaram a greve. Mas nós ainda não tínhamos assinado um acordo com a COMLURB, com a prefeitura para que não houvesse retaliações e nem demissões e perseguições. E o sindicato não esperou a assinatura deste acordo, e por eles terem sido a maioria numa assembleia esvaziada, decretaram o fim da greve sem a garantia de proteger os trabalhadores. A greve deveria ter tido continuidade até assinarmos este acordo.

Infelizmente nem o sindicato nem a COMLURB fornecem esses dados aos trabalhadores. Mas o que estamos vivendo agora em 2015, segundo os dados, informações vindas da base, é que temos mais de 70 trabalhadores demitidos pós-greve em 2015. Primeiro começou com as transferências, os trabalhadores que moravam em Santa Cruz eram mandados pro Centro da cidade, quem morava no Centro mandavam pra Santa Cruz, ou para locais longínquos, para dificultar que o trabalhador chegasse no horário pra justificar uma demissão por justa causa. Como os trabalhadores haviam cumprido essas determinações, eles não viram como achar chances para poderem mandar os trabalhadores embora, para retaliar, a COMLURB e a Prefeitura, não reconhecendo que nascem dentro da categoria novas lideranças que possam mudar o quadro da conjuntura dos trabalhadores, começaram a demitir os trabalhadores por justa causa.

Fiz parte de uma chapa no qual eu era candidato a presidente da chapa 2 UNIDOS PODEMOS MAIS - e sofremos uma fraude por parte do sindicato. Há 30 anos esse sindicato está ali, sempre houve chapa única, a dança das cadeiras, mas com muita dificuldade e empenho conseguimos registrar uma chapa para compor o sindicato. Infelizmente não conseguimos levar em virtude da fraude, porque o sindicato não emite os documentos necessários para que haja uma eleição democrática, transparente, e isso 
se encadeia na vitória deles, porque eles praticam a fraude. E o mais admirado é que numa categoria que tem 24 mil trabalhadores na COMLURB, acredito que mais de 80 mil da iniciativa privada, temos associados no nosso sindicato, sindicalizados, apenas 2.705 trabalhadores, ou seja, o nosso sindicato não tem coro, nosso sindicato não tem diálogo com a base, nosso sindicato não tem realmente um programa que venha atender a categoria, nosso sindicato está voltado para a Prefeitura, voltado para a COMLURB.

Eles blindam esses dois órgãos a fim de se beneficiarem, apenas a cúpula do sindicato é a fím de enfraquecer o nosso movimento de luta. É um regime escravocrata onde temos aí o fazendeiro que é o prefeito, a casa grande que é a Prefeitura, o senhor de engenho que é a COMLURB e temos o capitão do mato que é o nosso sindicato.

SNS: Você falou da invisibilidade da categoria dos garis, mas de fato podemos perceber que em 2014 parte dessa invisibilidade foi rompida. Então a greve de 2014 foi um ato importante da história do trabalhador no Rio de Janeiro, não só dos garis, mas do Rio de Janeiro. Por isso, gostaria que você falasse mais de como foi esse processo de organização para a luta de 2014, porque você fala aqui, de maneira muito clara, que o sindicato foi um obstáculo para essa luta. Como é que vocês conseguiram romper esse obstáculo e os outros obstáculos para fazer aquela luta que marcou de maneira tão significativa a história recente de luta do Rio de Janeiro?

CV: Veja bem, companheiro. Somos 24 mil funcionários, 12 mil garis, insatisfação total na categoria ao longo dos anos que se passaram em virtude das negociações. Todos os acordos coletivos, por mais que tivesse assembleia, o sindicato passava por cima da categoria e assinava o acordo sem o consentimento da base. Dificilmente nós tínhamos condições de nos organizarmos junto à base por serem muitas gerências, mais de cem gerências que tem a lotação dos trabalhadores. Graças à tecnologia, à informática, nos aproximamos. Poucos conseguiam um computador, ter acesso às redes sociais, mas começamos a nos comunicar, e através das redes sociais nós passávamos as informações e começávamos a marcar, e nos organizar através das redes sociais, marcar locais pra discutirmos o que fazer no próximo dissídio. Sabíamos que o sindicato, novamente, iria nos passar a perna. Nos organizamos, houve a assembleia. Nessa assembleia decidimos que não iríamos mais aceitar a interferência do sindicato. O sindicato não acreditou, assinou um acordo sem o nosso consentimento, nós marcamos uma reunião na Central do Brasil, pelas redes sociais, e as pessoas que tinham acesso se tornaram agentes 
multiplicadores de sua base. Nos organizamos na Central do Brasil e ali começamos a tirar possibilidades da greve. No momento que o sindicato assinou aquele acordo, que não contemplava a categoria, fomos tirar satisfação, dizendo ao sindicado que nós não tínhamos em assembleia discutido aquele acordo, nós queríamos a greve e o sindicato tinha que puxar um movimento de greve. Reunimos mais de 500 trabalhadores, fomos ao sindicato e, com a pressão da base, o sindicato assinou o acordo de greve mesmo já tendo assinado o dissídio sem nos consultar. Enfim, esse acordo foi assinado e foi levado para a base, e em menos de $24 \mathrm{~h}$ o sindicato emitiu um outro documento dizendo que a greve era considerada ilegal porque não tínhamos cumprido o aviso prévio de $72 \mathrm{~h}$. Mas o primeiro documento dizia que a greve estava decretada e que tínhamos que comparecer à porta do sindicato. Quando chegamos lá, aguardamos a presença dos diretores. Eles não compareceram. Ficou visível a não representatividade do sindicato, ali decidimos criar uma comissão de greve de forma democrática, onde os trabalhadores deveriam escolher 10 companheiros. Esses 10 companheiros foram escolhidos pela base e a partir dali quem determinava todas as ações era a categoria. A comissão de base não poderia tomar nenhuma decisão sem antes passar pela base. A comissão era apenas uma representação, mas quem comandava todo o movimento eram os trabalhadores.

A visibilidade ocorreu num momento oportuno de carnaval no Rio de Janeiro, o lixo se acumulou, o cidadão percebeu que o lixo estava se acumulando, a cidade passou a feder, e ali se descobriu que existia um profissional de limpeza urbana. Onde estava o gari, com a cidade fedendo e o lixo esparramado no chão? A nossa greve começou no carnaval. A sociedade sempre foi, a sociedade não. O cidadão sempre foi solícito com os trabalhadores, porque o gari e o cidadão interagem muito no seu dia a dia. E a sociedade percebeu que aquele gari que limpa a rua de suas casas estava reivindicando direitos, e nós conseguimos ganhar a cidade. A cidade se tornou, até hoje, o nosso maior advogado na nossa luta. Dentro do nosso sindicato temos o setor jurídico, mas não luta ao nosso favor. Quem luta ao nosso favor é a população de nossa cidade, que são os nossos verdadeiros advogados que nos apoiam em nossas lutas. Nós passamos a nos tornar visíveis no momento em que a cidade fedeu. Ali o cidadão, a sociedade percebeu que existia um profissional que limpava as ruas e que eles deixaram de limpar as ruas para lutar pelos seus direitos, por melhores condições de trabalho e condições salariais. Aí apareceu o gari, o trabalhador que cuida da cidade, o trabalhador que zela pela cidade, o trabalhador que faz o trabalho preventivo para que a cidade não fique doente. $\mathrm{O}$ gari, naquele momento, havia acordado e havia despertado para o cidadão que o trabalho que 
há muitos anos foi criminalizado, era de grande importância sim! Porque as pessoas, quando eu era adolescente, diziam assim "Se você não estudar, vai virar gari”, ou seja, não viam a importância do trabalho do gari, a importância que o gari tem para a cidade. A importância que o gari tem para a cidade está em fazer o trabalho preventivo para que a cidade do Rio de Janeiro, não somente a cidade do Rio de Janeiro, como as cidades do Brasil, os garis que trabalham no Brasil, não venham a ficar doentes. Então, se há lixo, há doença. Se há o gari que limpa, evitamos e limpamos a doença.

SNS: Em 2014, como é que se deu a relação da comissão de greve com o próprio sindicato, com a categoria você já falou um pouco sobre isso, e com a COMLURB e a Prefeitura?

CV: A comissão de greve foi eleita pela base, porque a categoria confiou nos dez. Tivemos a primeira experiência de fazer as negociações.

SNS: No caso ela foi eleita durante um ato...

CV: Um ato...

SNS: Em frente ao sindicato...

CV: Em frente ao sindicato. E essa comissão, tinha que respeitar os trâmites que foram abordados na base e qualquer determinação tinha que ser feita pela categoria, ela decidiria o que teria que ser feito. Foi uma experiência única naquela época importante, porque começamos a negociar. A primeira negociação foi com o sindicato. Chamaram a gente para dentro da prefeitura, quando chegamos dentro da prefeitura quem estava lá era a direção do sindicato. Automaticamente falamos o seguinte "Não negociamos com o sindicato. Queremos negociar com a COMLURB ou com a Prefeitura. Estamos nos retirando dessa sala." Alguns colegas achavam que deveríamos permanecer e eu falei que não tinha diálogo com o sindicato. Um sindicato que decreta uma greve e depois fala que a greve é ilegal e depois vem querer negociar, e que já tinha nos passado a perna durante anos e anos? Não tínhamos nenhuma possibilidade de conversar com aqueles representantes do sindicato. No momento que nós falamos que íamos nos retirar, que levantamos da cadeira, apareceu automaticamente o presidente e os diretores da COMLURB. E vieram com a mesma proposta que o sindicato. Nós falamos o seguinte "A proposta que nós queremos e que foi decidido pela categoria é esta que está aqui". Dei ao presidente da COMLURB, ele pegou, deu uma lida, mas novamente ele leu a proposta deles. Eu falei "O senhor não entendeu. Nós estamos entregando a 
proposta da categoria. A proposta que nós queremos é essa.”. E ele falou que não haveria possibilidade de não negociar. E eu falei pra ele que não seríamos nós que iríamos decidir aquilo ali. Quem decidiria seria a categoria e a resposta ele ouviria da base. Nós descemos, passamos as informações para os trabalhadores, os trabalhadores lá embaixo gritando para o alto, dizendo "Não tem arrego, não tem arrego. E esse lixo vai feder". Voltamos e falamos que a categoria não aceitou a proposta. E continuamos nessas manifestações, passeatas. Tivemos depois uma negociação chamada pelo defensor público Nilson Bruno Filho, defensor público do estado que na época estava tentando intermediar a negociação entre os trabalhadores e a COMLURB. Os 10 subiram novamente à Prefeitura e, acredito eu que, particularmente, ele se utilizou de táticas psicológicas, e ele conseguiu comover nove trabalhadores, eram 10 na comissão, ele conseguiu hipnotizar dez trabalhadores dizendo o seguinte "Termine a greve. Não vai haver demissões." Porque já havíamos tido várias, os trabalhadores estavam recebendo por sms as demissões, e outros recebendo cartas. Ele falou "Vocês se terminaram a greve agora, ninguém vai ser demitido. E eu prometo abrir uma lacuna no canal de negociações entre a COMLURB e a base. Vocês já são vitoriosos por terem feito esse movimento, aceitem os oitocentos e pouco. Já são vitoriosos por terem feito isso tudo e vocês não vão sair daqui como perdedores, vão sair daqui como os grandes vitoriosos." Eu automaticamente vi ali que os trabalhadores estavam alegres, conseguiram incorporar o argumento do defensor público, e pedi a palavra e falei o seguinte "Senhor defensor, eu respeito a proposta do senhor, respeito os meus colegas que estão aceitando a proposta do senhor. Mas não concordo com a proposta do senhor. A proposta do senhor não contempla a categoria e por outro lado nenhum trabalhador que está aqui pode se comprometer a aceitar a proposta do senhor. Eu peço licença a todos e vou me retirar dessa sala porque não tem proposta nenhuma que venha nos beneficiar, e quem vai decidir vai ser a categoria." Só faltou os companheiros que estavam ali me darem porrada, cara. Enfim, descemos e fomos passar pra categoria o que ocorreu na reunião. De forma fiel, companheiro Ivanir, conhecido como professor, passou pra categoria todas as palavras do defensor Nilson Bruno Filho. E eu olhava pra cada trabalhador que estava ali, nos olhos de cada um o espanto de termos caminhado alguns dias de tanta luta, termos nadado, nadado e morrermos na praia. Pedi o microfone, tentaram não me dar, consegui pegar e falei o seguinte "Quem decide é a base. Eu Célio, gari, por mim a greve permanece. Não devemos aceitar essa proposta, porque não fizemos uma luta pra chegarmos aqui com uma proposta derrotada." A 
categoria explodiu e falou novamente "Não tem arrego. A greve continua e vamos à luta." Naquele momento de euforia, de satisfação da continuidade da luta, aquela comissão foi quebrada e foi escolhida uma outra comissão. Os trabalhadores se retiraram da comissão, voltaram para seus locais de trabalho, e nós, trabalhadores, que estávamos numa luta, demos continuidade e foram escolhidos outros companheiros. E assim foi a nossa caminhada até chegarmos ao Tribunal Regional do Trabalho numa audiência de emergência, onde foram feitas as negociações. Mas respeitando a base. Nunca desrespeitando a base. A base que manteve a greve. A base que determina porque, no meu ponto de vista, o movimento de greve só tem legitimidade quando os trabalhadores, de forma unificada, saem para reivindicar os seus direitos. Então, era direito nosso respeitar a categoria. E assim foi feito. As propostas que Pedro Paulo lá no Tribunal Regional do Trabalho tentou nos oferecer, também eram de um salário muito baixo. Eu dizia pro Pedro Paulo que não era eu que decidia, ele insistia dizendo "Célio, é você que decide", eu dizia "Não sou eu que decido. O senhor está enganado, quem decide é a categoria." E ele, insistentemente, insistia que era eu quem decidia, eu dizia "Não sou eu que decido. Quem decide é a categoria. O Senhor está equivocado. Vou provar que não sou eu, que é a categoria", ele falou "Oferece lá aos trabalhadores esse valor de oitocentos e poucos reais." Eu falei "Eu posso levar a proposta do senhor, mas acredito que a categoria não vai aceitar." Levamos a proposta e a categoria falou “Também não vai ter arrego." Voltei lá pra cima, falei pra eles "Vou ouvir lá debaixo se o trabalhador vai aceitar ou não." Subimos, eles ouviram e eu falei "A proposta que nós temos é de mil e duzentos reais. É o que a categoria quer.” Aí levei outra proposta chula, aí falei "Não, é mil e duzentos reais que nós queremos, e mais os benefícios." Benefícios esses que eram o décimo quarto salário, plano odontológico, hora extra sempre nos domingos e feriados, uma série de benefícios que realmente vinha contemplar a categoria. Eles vendo que a categoria não estava arredando o pé, resolveram aceitar. Foi uma luta muito dura com eles, porque esse governo reluta para não valorizar o trabalhador. E nós também de forma unida e organizada lutamos para garantir os nossos direitos. Não conseguimos os mil e duzentos reais, mas conseguimos mil e cem reais, o ticket no valor de vinte reais e os outros benefícios. E foi firmado. Mas deixamos bem claro pra eles "Estamos saindo do movimento de greve, mas assinem um documento impedindo retaliações e demissões. Vou levar a proposta pra categoria. Eu acho que, talvez, a categoria aceite. Não posso afirmar pro senhor, mas se a categoria aceitar a gente vai terminar, mas diante dos acordos de não retaliações e 
demissões." Levamos a proposta pra categoria. A categoria satisfeita, e nós voltamos com a resposta, a categoria tinha aceito. Mas que todos os documentos tinham que ser assinados. Enfim, quem decidiu não foi o Célio. Quem decidiu não foi a comissão. Quem decidiu foram os trabalhadores. Isso.

SNS: Uma coisa que muitas pessoas comentam é que 2013 foi um ano de muita mobilização, com muita luta. Foi contra o aumento das passagens dos transportes urbanos que ocorreu um grande movimento no dia 20 de junho de 2013, reuniu certamente mais de dois milhões de pessoas na Presidente Vargas. E algumas pessoas falam que o movimento dos garis ou foi influenciado, ou foi uma continuidade daquela luta. Tem alguma veracidade essa afirmação? Como é que você vê o movimento de 2013 influenciando a luta de 2014 ?

CV: Com certeza. É uma grande influência sim, porque, no meu ponto de vista, antes do companheiro ser gari, ele é cidadão. E ele, como cidadão, tem filhos, esposa, seus filhos estudam em instituição pública de ensino, utilizam o transporte público, utilizam o SUS, Sistema único de Saúde. E ali se falava a linguagem do trabalhador gari. Ele é gari porque ele faz a limpeza, mas ele é cidadão como qualquer outro, e ali expressava também o desejo do trabalhador gari. Isso nos inspirou porque se a população acorda pra reivindicar um direito, por que nós na qualidade de trabalhador também não podemos se levantar e lutar por direitos, que muitas das vezes o governo nos tira? Com certeza influenciou bastante, até porque o que nos chamou atenção foi que a manifestação de junho não tinha uma direção partidária, não tinha a direção de sindicatos. O povo se levantou pelo povo. E nós garis também fizemos a mesma coisa. O gari se levantou pelo gari. A base foi pela base, e não pelo velho aparato, que hoje 99\% não está a serviço dos trabalhadores. Junho foi muito importante pro nosso movimento de greve, foi um impulsionador, no meu ponto de vista. $\mathrm{O}$ que a população pleiteava, era o que a gente pleiteava, melhores condições de trabalho, melhores condições salariais, porque também nos tiram direito social. Então, junho foi o DNA de todos os movimentos, no meu ponto de vista, e que nos deu coragem e nos impulsionou, ou seja, o povo consegue trazer a energia pro povo, e esta energia, quando é passada de cada um, desencadeia o que ocorre, é a população lutando e reivindicando. Nós, garis, não temos medo da multidão, queremos continuar nas ruas. E torço pra que essa multidão volte pras ruas. 
SNS: Comparando os momentos de 2014 e 2015 no movimento dos garis, você encontra alguma coisa diferente? Mudou alguma coisa?

CV: Com certeza mudou, companheiro. Ela muda desde o momento em que um trabalhador que batia seu cartão, trabalhava, batia o seu cartão e retornava à sua casa, quando tinha um aumento que não era significante, não reclamava e ficava por isso mesmo. E no momento que ele descobre que existe um oxigênio, ele pode respirar e passa a discutir política. O gari passou a discutir política, passou a fazer análise da conjuntura brasileira, passou fazer análise dos problemas do Rio de Janeiro, na cidade que nós habitamos, e começou a fazer a comparação dos deputados federais, senadores, vereadores, prefeitos eleitos, o que eles nos representam, quem faz pelo povo e quem não faz. E a discussão se tornou mais ampla e até hoje, companheiro, o gari passa a discutir política. Obtendo visibilidade até nas redes sociais, vemos o gari falando que o prefeito tá fazendo isso, o prefeito não tá fazendo aquilo, o deputado x, o deputado y, que precisamos melhorar a luta e apoiando outras lutas. Vejo, hoje em dia, os garis apoiando a luta dos professores. Tem garis apoiando a luta do pessoal da saúde. Ou seja, o gari hoje tem um entendimento político bastante intenso, até porque nós queremos uma cidade diferente que essa que nos é apresentada. Queremos o novo. Queremos um sindicato de novo tipo. Queremos fazer parte da política, não como coadjuvante, mas como cidadão. Queremos estar mais próximos desses debates e dessas discussões, porque só estando próximos vamos trocar conhecimentos e fazer valerem nossos direitos. O trabalhador descobriu que a COMLURB é uma empresa política e, por ser política, oprime o trabalhador de forma política, e nós trabalhadores aprendemos que através da política podemos combater a opressão politicamente.

SNS: Obrigado, Célio. Só para finalizar, alguns aspectos. Antes de trabalhar na COMLURB, você trabalhou onde? Fale um pouco da profissão dos seus pais, se quiser falar. A sua escolaridade, até quando você estudou, onde você estudou.

CV: Companheiro, eu fui um ex-aluno da FUNABEM durante quinze anos. Não conheci meus pais. Tenho filhos, mas procuro não falar sobre a questão dos meus filhos, deixo meus filhos fora dessas questões, minha família. Digo a você que eu fiz a universidade do mundo e tenho doutorado nela também. 